\title{
INVESTIGATION OF PHYSICOMECHANICAL PROPERTIES AND TEMPERATURES OF TRANSFORMATION OF IRON-BASED ALLOYS
}

\author{
Saenkov K.L. \\ Dep. "Materials, Technologies and Design of Machines", \\ Perm National Research Polytechnic University \\ Perm, Russian Federation \\ severskl@mail.ru
}

\begin{abstract}
Investigations of powder alloys of the Fe- (30-36)\% $\mathrm{Ni}$ system based on carbonyl powders are presented. When studying the microstructure of $\mathrm{Fe}-(30-36) \% \mathrm{Ni}$ alloys, it was found that an increase in the concentration of nickel promotes the coarsening of the average grain size of the austenite, and the grain coarsening promotes the acceleration of the austenitic martensitic transformation. In alloys with nickel content in the range of $30-32 \%$, the phase transformation temperature increased with increasing a minimum grain size of martensite in direct proportion to the nickel content. The critical austenite grain size was 1-3.5 microns. It is established that the transformation in alloys with $30.3-31.93 \%$ of nickel occurs in a wide range of temperatures (70-120 degrees), and in alloys with $34.35-36.33 \%$ of nickel - in a narrow one (1-2 degrees). It is shown that as the nickel content increases from 30 to $36 \%$, the grain size increases and the temperature of the phase of $\mathrm{Y}$-a transformation increases by $75 \mathrm{~K}$. The fraction of martensite formed increases by a factor of 5 . It was found that the decomposition of austenite in iron nickel alloys (30-32\% $\mathrm{Ni}$ ) was in the range of $70-92 \%$, with a $\mathrm{Ni}$ content of $33-36 \%$; the decomposition of austenite was insignificant: $2-15 \%$. It was established that when the samples were cooled to $5 \mathrm{~K}$ in a field with a strength of $5 \mathrm{kE}$, the value of the magnetization increased to 113-189 emu / g. It was found that a decrease in the critical grain size provokes the transformation in alloys.
\end{abstract}

Keywords- alloys, properties, phase, austenite, martensite, structure.

\section{INTRODUCTION}

Martensitic transformation (MT) is the most interesting stage of transformation of austenite in steels and alloys [1]. During the $\mathrm{Y}^{-} \alpha$ transformation process, martensite crystals are transformed to austenite grains over specific crystallographic planes and the interphase boundary does not appear in this case. At a given phase transformation, the oriented and batch shift of atoms in the austenite crystal lattice proceeds synchronously [2].

Superplasticity, superelasticity, shape memory effect and other abnormal mechanical properties of alloys are somehow connected with this transformation [3]. The notion of "martensitic transformation" emerged during the study of processes occurring during the rapid cooling of steels leading to a certain structure and high strength properties. In the second half of the twentieth century, the features of austenitic-

\author{
Oglezneva S.A. \\ Dep. "Materials, Technologies and Design of Machines", \\ Perm National Research Polytechnic University \\ Perm, Russian Federation \\ osa@pm.pstu.ru
}

martensitic transformations were formulated. Among these features, there is diffusion, shear character of the phase transformation, the rapid development of the transformation at low temperatures, the dependence of the martensite amount on temperature, and the specific "martensitic" structure [4].

To realize the martensitic transformation, first of all, it is necessary to subject the alloy to a rapid and continuous cooling below the starting point of the $\mathrm{Y}^{-\alpha} \alpha$ transformation $\left(\mathrm{M}_{\mathrm{s}}\right)$ [5]. The lower the $M_{s}$, the higher the probability of the appearance of $\alpha$-phase crystals. The amount of martensite that has arisen is growing as a result of the appearance of the newest crystals, and not as a result of the growth of existing crystals [6].

The temperature of the end of the transformation is denoted as $M_{f}$, the patterns of atomic rearrangement for $y-\alpha$ transformations follow from certain crystal-geometric relationships between the crystal lattices (structures) of the $Y$ and $\alpha$-phases [7]. As a result of austenitic-martensitic transformation from one orientation of the austenite phase (grain, mono-crystal), 24 orientations of the martensitic phase can be obtained [8].

The amount of $\alpha$ phase, in comparison with austenitic, is dominated by the largest specific volume. In the manufacture of steels and alloys, it is necessary to observe arising $\alpha$ - phase [9]. Since an increase in martensite is the cause of the formation of internal stresses while carrying out heat treatment, these stresses in turn contribute to the appearance of deformation of the material and the formation of cracks in it.

To illustrate the description of all processes of $\mathrm{Y}-\alpha$ transformations, three basic approaches can be used: crystallographic, thermodynamic approaches, and dynamic wave theory.

The crystallographic approach implies all the basic physical mechanisms of the austenite-martensitic transformation, for example, the deformation of austenite, which converts the original lattice of austenite into a martensite lattice [10].

All transformations of the martensitic type have a number of common features among themselves, such as the pattern of displacements of atoms relative to each other, the directivity of 
these displacements during the process of rearrangement of the crystal lattice of the initial phase into a new (forming) phase and the cooperativity of atomic displacements. These features lead to macroscopic displacement and the appearance of relief on the surface. The results of G.V. Kurdyumov lead to the determination of martensitic transformation - "Martensitic transformation consists in the regular restructuring of the lattice, in which atoms do not exchange with places, but only shift relative to each other over distances not exceeding interatomic".

The thermodynamic approach implies that under the conditions of supercooling, a diffusion decomposition of austenite into a ferritocarbide mixture can not occur, which brings the system to an absolute minimum of free energy. [9].

In alloys with the lowest martensitic point, the transformation during cooling is a series of small explosions, and there is no increase in the amount of martensite at a constant temperature. Lowering the temperature does not slow down this transformation and increase the cooling rate accordingly, it does not allow delaying the formation of martensite.

The dynamic wave theory of the $\mathrm{Y}^{-\alpha}$ transformation is based on the concept of heterogeneous nucleation and controlled wave growth. The theory implies that the transformation does not begin at the grain boundary, but occurs at some distance from it, namely in the volume of the grain. The point of onset of the nucleation of $\alpha$-phase crystals is dependent on the propagation along the grain of elastic deformations, which are caused by the presence of defectsdislocations. Grain, having a minimum size, in which dislocations can not fit, in turn will not support the phase transformation [11].

To date, many works have been published both for interpreting the features of austenitic-martensitic transformation, related to the carriers of threshold deformation, and for creating a dynamic approach to the theory of the formation of martensite crystals. The idea of a theory additional to the thermodynamic approach is reduced to deciphering the dynamic structure of the excited state of the lattice in the nonequilibrium front region of the nonlinear transformation wave [12]. One of the scenarios for the growth of martensite from the position of the wave theory indicates that in the regions adjacent to the boundary, when a martensitic crystal interacts with a boundary, dislocations may be generated, which become the centers of nucleation of a new martensitic crystal [13].

All the theories and approaches to the description of martensitic transformations that exist today can be applied depending on the composition of the material and the technologies for its production [14]. The aim of this work is to study the physico-mechanical properties and temperatures of phase transformations of alloys of the Fe - Ni system [15].

\section{METHODS}

To produce samples of powder alloys of the Fe-Ni system, the authors used carbonyl iron powders - grade VMS-1, carbonyl nickel - grade PNK UT-3. The powders were mixed for 8 hours in a mixer, with a shifted axis of rotation. The blanks were pressed in a mold on a hydraulic press $\mathrm{P}-125$, at a pressure of $600 \mathrm{MPa}$.

The sintering of the samples was carried out in a vacuum electric furnace SSHV-4.5.5/12-IC1. Annealing was performed at to $=900^{\circ} \mathrm{C}$ for 1 hour. The samples were press at $600 \mathrm{MPa}$; the cycle was repeated twice. Sintering was carried out in vacuum and argon media at $\mathrm{t}^{\circ}=1200^{\circ} \mathrm{C}$, in total, for 20 hours [16]

To detect the microstructure (austenite grain and martensitic phase), used thermal etching of the sample surface in a vacuum medium at $t \circ=1000^{\circ} \mathrm{C}$ was used for 30 minutes. The microstructure images were obtained through an optical microscope Axiovert and an analytical, scanning, electron microscope ULTRA 55/60 Carl Zaiss, with a resolution of 1 $\mathrm{nm}$, equipped with an INCA spectral analyzer [17].

The microhardness of the austenite and martensitic phases was measured with PMT-3, at a load of $0.5 \mathrm{~N}$, in accordance with GOST 9450-76, the measurement error was not more than $10 \%$. The grain sizes were calculated by measuring the length of chords in accordance with GOST 5639-82 on microstructure images with a magnification of 200 times, as well as using specialized software (Gwydion SoftWare). X-ray phase analysis of samples of powder alloys was obtained using a Shimazu XRD 6000 diffractometer in $\mathrm{K}-\alpha-\mathrm{Cu}$ radiation. Decoding the diffractograms was carried out using the ICDD PDF-2 map file. The hardness of the powder alloys after sintering was measured using the Brinell method [18].

The tensile strength and Young's modulus were determined on INSTRON 5885 [19]. The impact strength was determined in accordance with GOST - 9454-78 at room and negative $\left(-190^{\circ} \mathrm{C}\right)$ temperatures. The magnetometric method was used to study phase $\mathrm{Y}^{-} \alpha$ transformations in powder alloys of the Fe- (30-36)\% Ni system. Samples of alloys after sintering were magnetized in an increasing magnetic field: from 0 to $5 \mathrm{kE}$, at room temperature, after which the samples of the alloys were supercooled to $5 \mathrm{~K}$ in a field with a strength of $5 \mathrm{kE}$. The magnetization of the samples increased to 113 $189 \mathrm{emu} / \mathrm{g}$, because of the appearance of additional magnetization of the $\alpha$ phase, which in turn was formed as a result of supercooling of the alloys.

\section{DISCUSSION AND RESULTS}

$\mathrm{X}$-ray phase analysis showed that an austenite structure was formed in all the alloys after sintering. The grain structure of sintered alloys $\mathrm{Fe}-30 \% \mathrm{Ni}$ and $\mathrm{Fe}-36 \% \mathrm{Ni}$ is shown in Fig. $1 \mathrm{a}, \mathrm{b}$. The structure is characterized by heterogeneity, pores are visible in the structure, twins are present in the grains, which indicates the presence of austenite. The histograms of the grain size distribution are shown in Fig. 1c, d. 

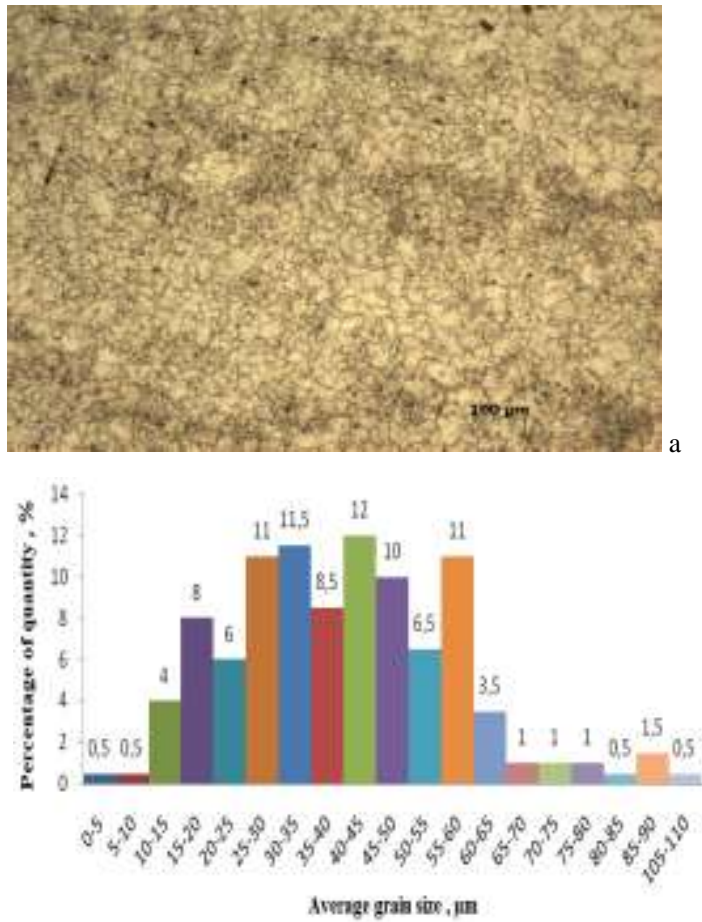

b
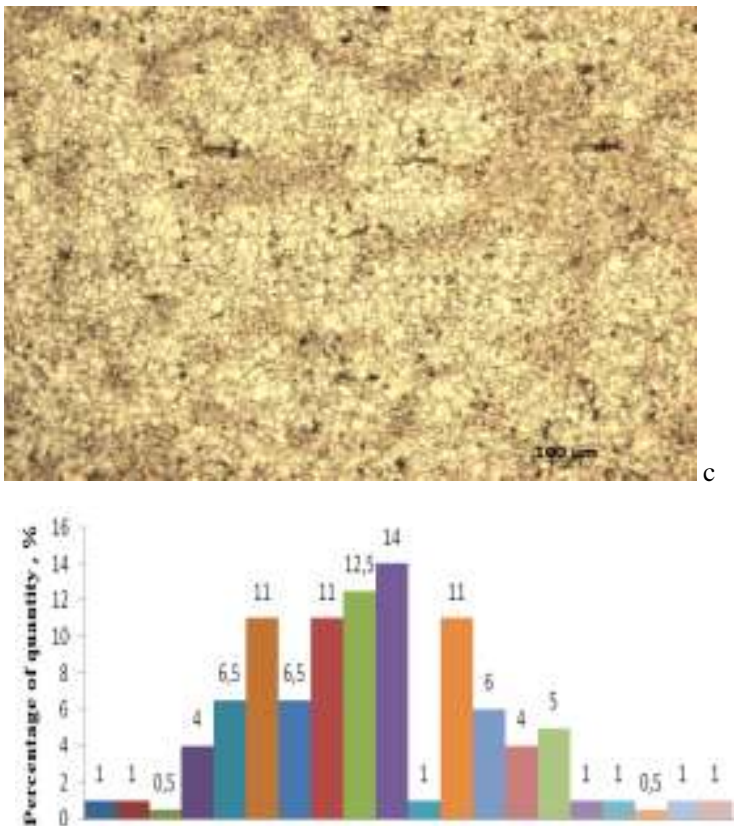

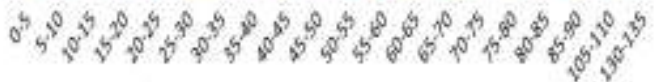

dverge grain sixe, in

Fig. 1. a, b: photographs of the structure of $\mathrm{Fe}-30 \% \mathrm{Ni}$ and $\mathrm{Fe}-36 \% \mathrm{Ni}$ alloys, respectively, in g: histogram of grain size distribution in $\mathrm{Fe}-30 \% \mathrm{Ni}$ and $\mathrm{Fe}-36 \% \mathrm{Ni}$ alloys
TABLE 1. Physical and mechanical properties and grain size of Fe- (30-36)\% Ni samples after sintering

\begin{tabular}{|c|c|c|c|c|c|}
\hline № & $\begin{array}{c}\text { Ni } \\
\text { content, } \%\end{array}$ & $\begin{array}{c}\text { Microhardness } \\
\text { Y, MPa }\end{array}$ & $\begin{array}{c}\mathrm{P}, \\
\%\end{array}$ & $\begin{array}{c}\mathrm{KC}, \\
\mathrm{kJ} / \mathrm{m}^{2}\end{array}$ & $\begin{array}{c}\text { Average } \\
\text { grain size, } \\
\mu \mathrm{m}\end{array}$ \\
\hline 2 & 30.2 & 1610 & 5 & 807 & $33 \pm 15$ \\
\hline 4 & 30.5 & 1450 & 4 & 810 & $45 \pm 15$ \\
\hline 6 & 31.9 & 1452 & 2 & 817 & $39 \pm 13$ \\
\hline 8 & 31.6 & 1668 & 4 & 815 & $41 \pm 13$ \\
\hline 20 & 33.1 & 1478 & 5 & 829 & $39 \pm 9$ \\
\hline 30 & 34.3 & 1714 & 6 & 868 & $45 \pm 16$ \\
\hline 38 & 36.3 & 1620 & 6 & 880 & $52 \pm 16$ \\
\hline
\end{tabular}

After sintering the samples of powder alloys of the $\mathrm{Fe}$ $(30-36, \%) \mathrm{Ni}$ system, the residual porosity of the samples was $2-6 \%$, Table 1 .

The grain size in Fe Ni alloys increased,insignificantly wit $\mathrm{h}$ increasing nickel concentration: from 30 to $50 \mu \mathrm{m}$. It is established that an increase in the nickel content in alloys contributes to an increase in the toughness from 807 to $880 \mathrm{~kJ}$ $/ \mathrm{m}^{2}$. The microhardness of the austenite after sintering was 1450-1714 MPa, in proportion to the nickel content.

After cooling the alloys to $-190^{\circ} \mathrm{C}$ (cooling in liquid nitrogen) in iron-nickel samples with a $\mathrm{Ni}$ content of 33 to $36 \%$, the decomposition of austenite was insignificant (2$15 \%$ ), Table. 2 , in the structure after cooling, two phases are distinguishable: austenite and acicular martensite, Fig. 2

TABLE 2. Phase composition of the samples after cooling of the Fe- (30.236.3)\% Ni powder system

\begin{tabular}{|c|c|c|c|c|c|}
\hline \multirow[t]{2}{*}{ № } & \multirow{2}{*}{$\mathrm{Ni}, \%$} & \multirow{2}{*}{$\begin{array}{c}\mathrm{Y}^{-} \\
\text {phase, } \%\end{array}$} & \multirow{2}{*}{$\begin{array}{c}\alpha- \\
\text { phase, } \\
\%\end{array}$} & \multicolumn{2}{|c|}{$\begin{array}{l}\text { Microhardness after cooling, } \\
\text { MPa }\end{array}$} \\
\hline & & & & $\mathrm{A}$ & $\mathrm{M}$ \\
\hline 4 & 30.2 & 8 & 92 & 2110 & 2370 \\
\hline 8 & 31.6 & 30 & 70 & 1880 & 2440 \\
\hline 6 & 31.9 & 15 & 85 & 1940 & 2600 \\
\hline 20 & 33.1 & 85 & 15 & 2230 & 2800 \\
\hline 38 & 35.8 & 97 & 3 & 2300 & 3580 \\
\hline 28 & 36.3 & 98 & 2 & 2370 & 3810 \\
\hline
\end{tabular}



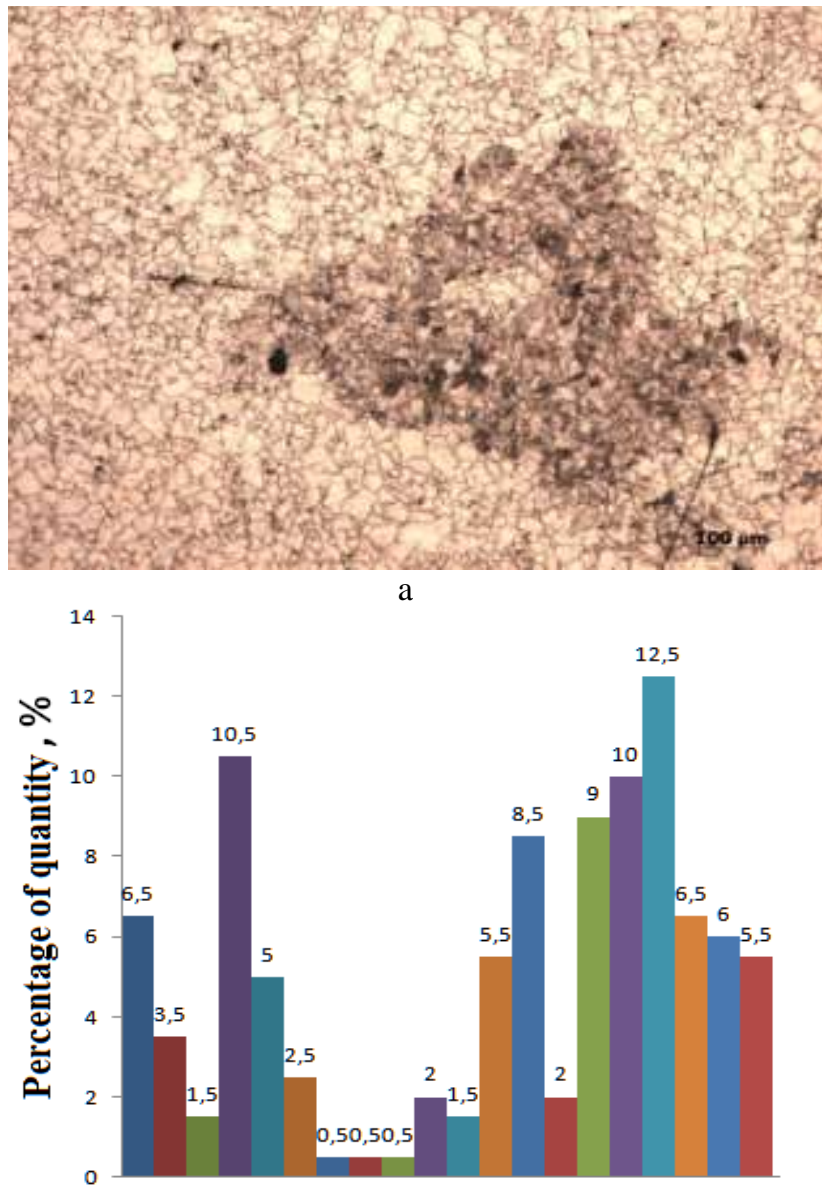

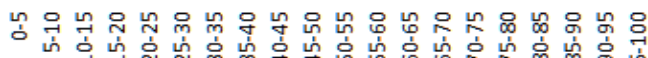

Average grain size , $\mu \mathrm{m}$

b

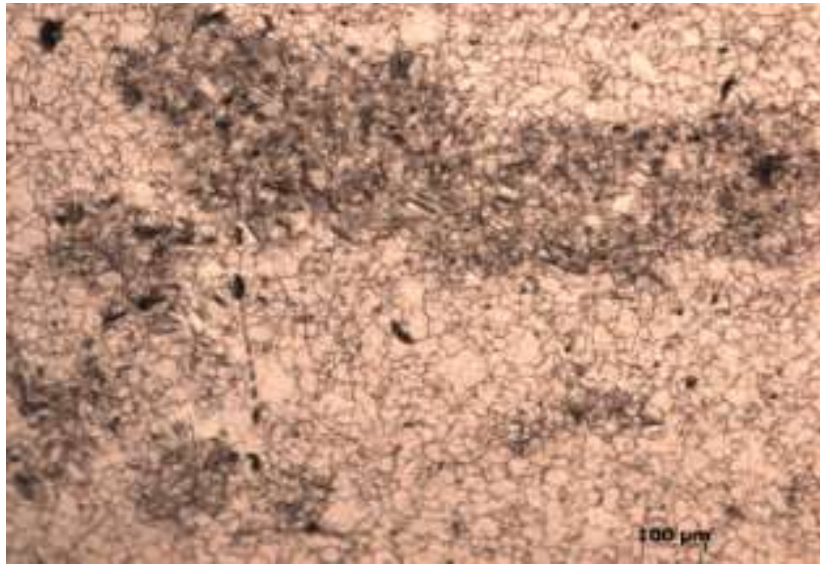

$\mathrm{c}$

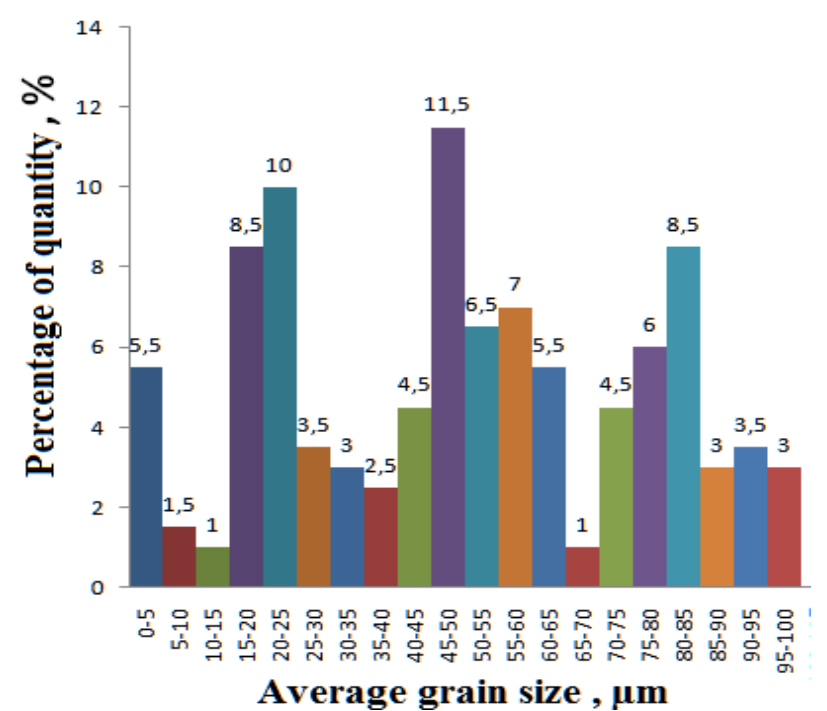

d

Fig. 2. a, b: photographs of the structure of $\mathrm{Fe}-30.296 \% \mathrm{Ni}$ and $\mathrm{Fe}-36.33 \% \mathrm{Ni}$ alloys after cooling, c, d: histograms of the distribution of austenite grains in size in alloys $\mathrm{Fe}-30.296 \% \mathrm{Ni}$ and $\mathrm{Fe}-36.33 \% \mathrm{Ni}$

After supercooling the samples, the microhardness of the austenite phase was measured, which was $1880-2370 \mathrm{MPa}$, as well as the resulting martensitic phase - 2370-3810 MPa, (Table 2), depending on the nickel content. Testing the toughness of alloys at $-190^{\circ} \mathrm{C}$ showed an increase in this strength characteristic to $350 \mathrm{~kJ} / \mathrm{m}^{2}$, with an increase in the nickel content from 30 to $36 \%$, Fig. 3 .

The hardness decreased insignificantly with increasing nickel content, apparently, the increase in porosity had an effect on the decrease in hardness, Fig 4. The microhardness of the alloys increased in proportion to the concentration of nickel, Fig. 5.

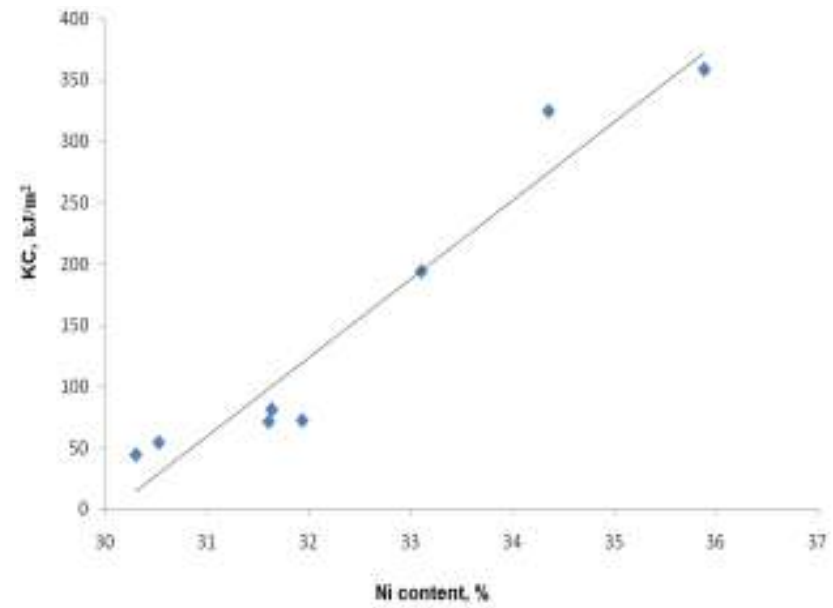

Fig. 3. Dependence of the toughness of samples of the Fe- (30-36)\% N system on the $\mathrm{Ni}$ content at $-190^{\circ} \mathrm{C}$ 


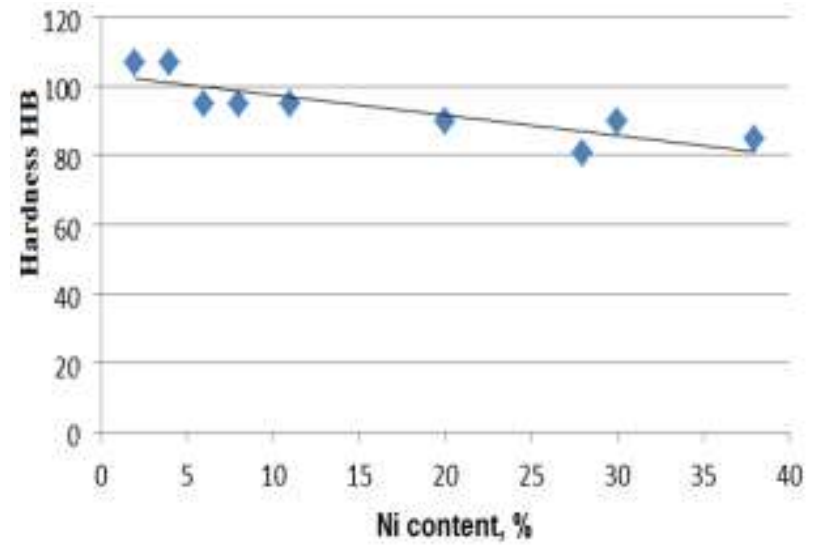

Fig. 4. Dependence of the hardness of samples of the Fe- (30-36)\% Ni system on the Ni content

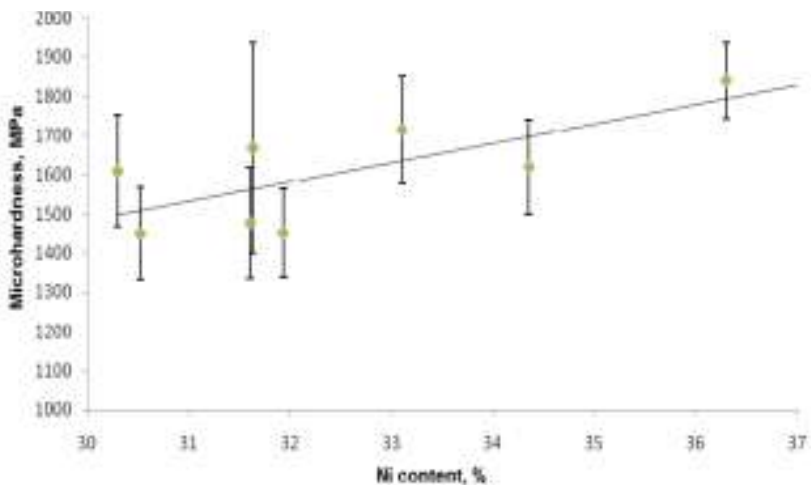

Fig. 5. Dependence of the microhardness of samples of the Fe- (30-36)\% Ni system on the Ni content

Young's modulus of iron-nickel alloys increased from 4700 to $5500 \mathrm{MPa}$, with an increase in the nickel content from 30 to $36 \%$, Fig. 6 , the tensile strength index decreased to an increase in the nickel concentration, the yield strength increased with increasing Ni content, Fig. 7. In Fe- (30-36)\% $\mathrm{Ni}$ alloys, the temperatures of the beginning and the end of the $\mathrm{Y}-\alpha$ transformation were determined by a magnetometric method (Table 3, Fig. 8).

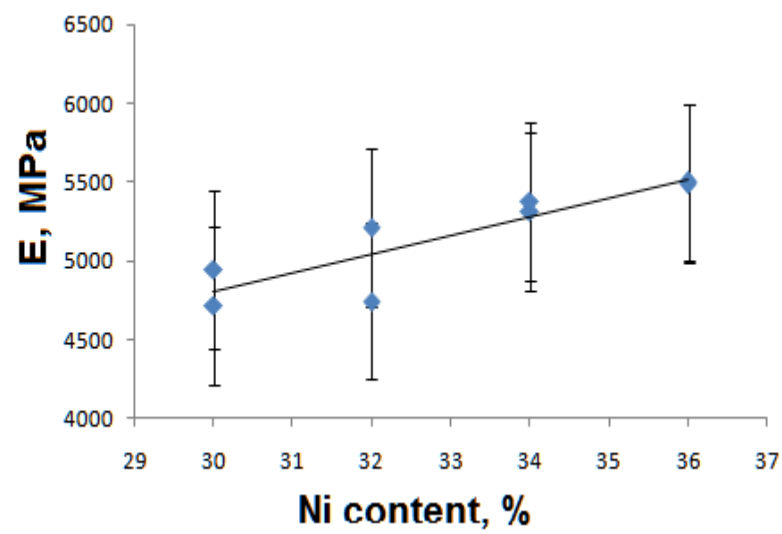

Fig. 6. Dependence of Young's modulus (E) of samples of the Fe- (30-36)\% $\mathrm{Ni}$ system on the change in the Ni content in alloys

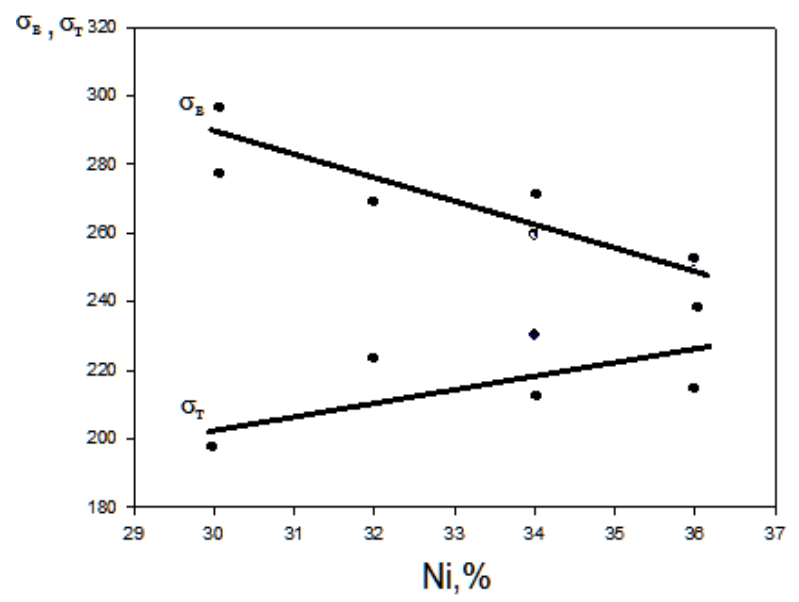

Fig. 7. Graphs of the ultimate strength and yield strength of the powder system samples: Fe- (30-36)\% Ni, depending on the concentration of nicke

TABLE 3. The temperatures of the beginning (T2) and the termination (T1) of the austenitic-martensitic transformation

\begin{tabular}{|l|l|l|l|l|l|}
\hline $\begin{array}{l}\mathrm{Ni} \\
\text { content.\% }\end{array}$ & $\mathrm{T}_{1,} \mathrm{~K}$ & $\mathrm{~T}_{2, \mathrm{~K}}$ & $\begin{array}{l}\mathrm{M}_{\mathrm{st}} \\
(\mathrm{emu} / \mathrm{g})\end{array}$ & $\begin{array}{l}\mathrm{M}_{\mathrm{fin}} \\
(\mathrm{emu} / \mathrm{g})\end{array}$ & $\begin{array}{l}d_{\mathrm{cr}}, \\
\mu \mathrm{m}\end{array}$ \\
\hline 30.3 & 58.2 & 169.2 & 43.1 & 189.5 & 1 \\
\hline 31.85 & 70.2 & 142 & 70.2 & 185.7 & - \\
\hline 31.93 & 55.2 & 173.3 & 71.6 & 185.4 & \\
\hline 34.35 & 109.2 & 111 & 113.8 & 177.9 & \\
\hline 36.33 & 134.2 & 135.5 & 148.3 & 170.4 & \\
\hline
\end{tabular}

Transformation in alloys with $30.30-31.93 \%$ nickel occurs in a wide range of temperatures (70-120 degrees), and in alloys with $34.35-36.33 \%$ nickel - in a narrow (1-2 degrees), Fig. 8 


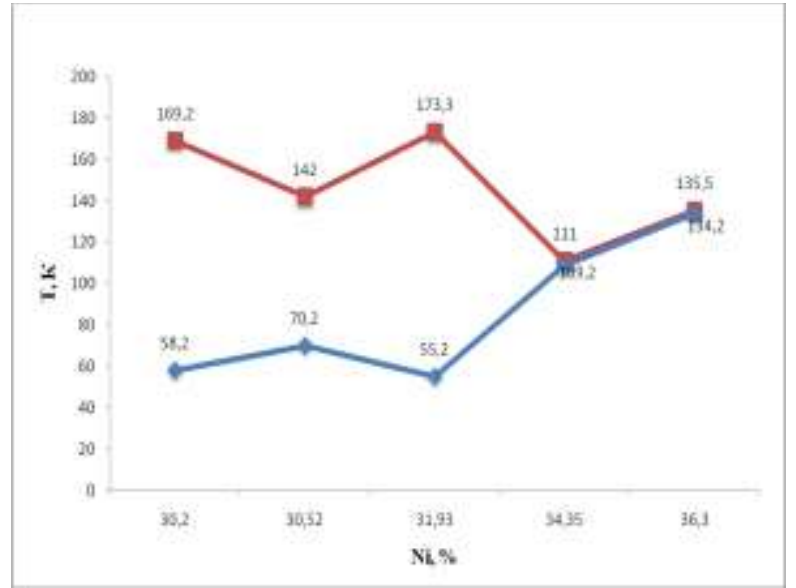

Fig. 8. Start temperature (upper graph) and finish temperature (lower graph) of austenitic-martensitic transformation in Fe- (30.2-36.3)\% Ni alloys

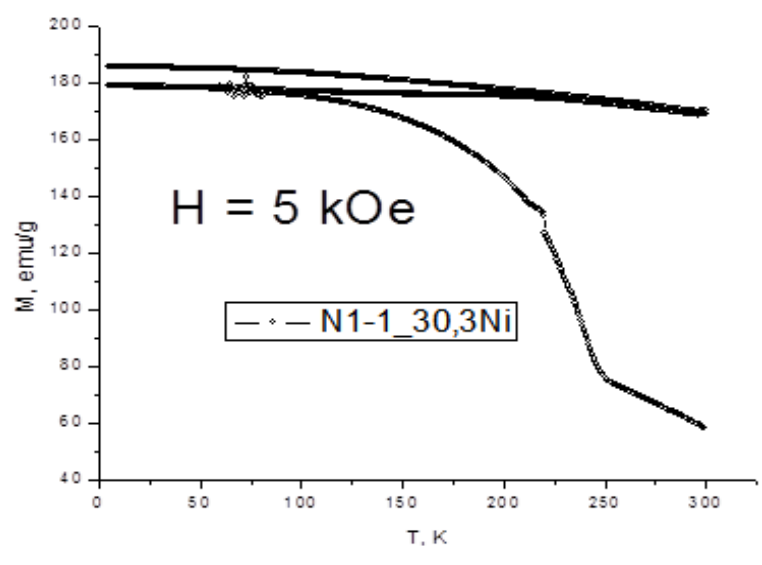

a

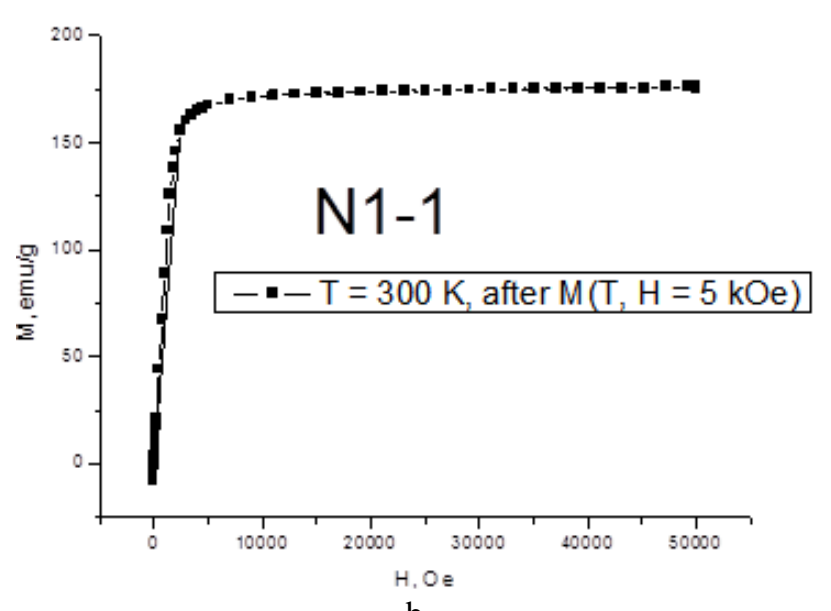

b

Fig. 9. Graphs of the magnetization of the alloy by the temperature (a), the field dependence of the magnetization at a constant $\mathrm{T}=300 \mathrm{~K}$ (b) sample Fe$30.29 \% \mathrm{Ni}$

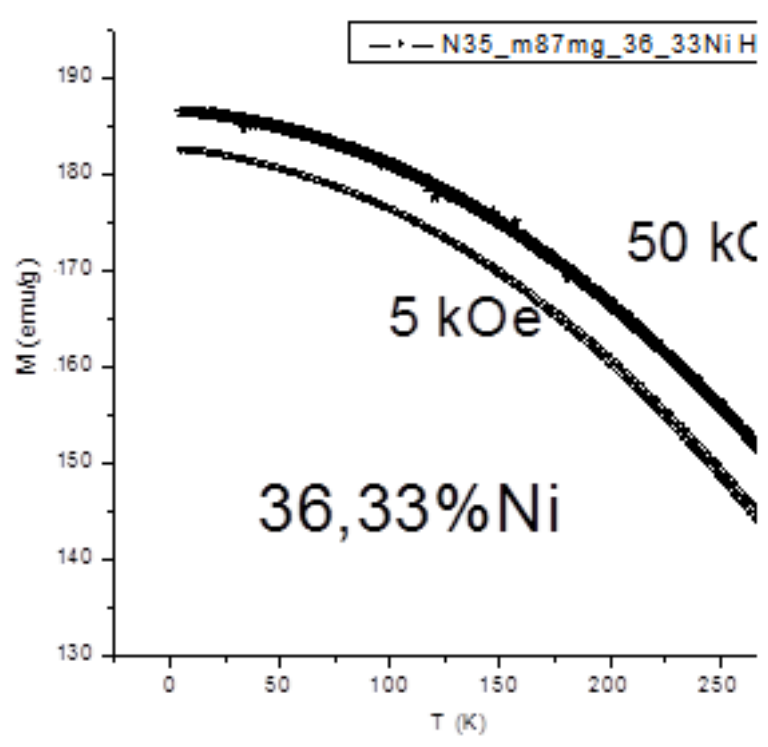

a

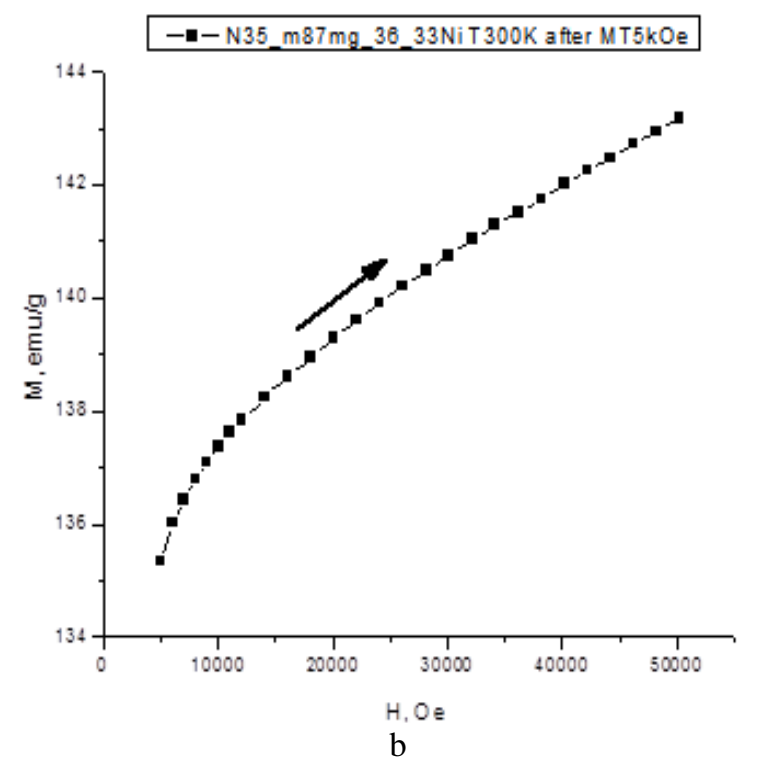

Fig. 10. Graphs of the magnetization of the alloy by the temperature (a), the field dependence of the magnetization at a constant $\mathrm{T}=300 \mathrm{~K}$ (b) sample Fe$36.33 \% \mathrm{Ni}$

This is due to the fact that in alloys with an increased nickel content, the transformation occurred in the grains of a narrow size range $(1-30 \mu \mathrm{m})$, and in the alloys with a reduced content, grains with sizes from $1 \mu \mathrm{m}$ to $60 \mu \mathrm{m}$ were tested. Probably, a certain temperature of the phase transformation, which agrees with the dynamic wave theory of austenitemartensitic transformation, corresponds to each size range.

In the process of cooling the samples to $5 \mathrm{~K}$, in a field with a strength of $5 \mathrm{kE}$, the value of the magnetization increased to 113-183 emu / g (Fig. 9-10), because an additional magnetization appeared from the appearance of martensite. The grain size distribution histograms (with maximum grain sizes up to $100 \mu \mathrm{m}$ ) shows that for the $\mathrm{Fe}-\mathrm{Ni}$ alloys with concentrations of $30.3 \%$ and $31.93 \%$, the critical De size is close to $1 \mu \mathrm{m}$ and $3.5 \mu \mathrm{m}$, respectively. 
The transition to concentrations of $34.35 \%$ and $35.33 \%$ is not accompanied by the appearance of a significant amount of martensite, an increase in the concentration of nickel leads to an increase in the temperature of the onset of conversion and a decrease in the temperature of the end of the transformation. Parameter Dc is not a constant within the framework of the microscopic theory.

When approaching $34 \%$ of nickel, Dc tends to infinity; initial point Ms tends to zero, and transformation does not occur independently of the single crystal. After the inclusion of a strong magnetic field, Dc significantly decreases - the transformation continues, the temperature of Ms increases - a transformation that did not initially exist appeared. This shows that already about $34.35 \%$ concentration is near critical value $\mathrm{C} *$, and the values of Dc (in accordance with the known histograms) are not less than $90 \mu \mathrm{m}$. This result is of fundamental character and agrees with the conclusions of the dynamic theory of martensitic transformations.

\section{CONCLUSION}

When studying the powder system Fe- (30-36)\% Ni alloys, it was found that as the nickel concentration increases, the hardness is reduced to $20 \%$, and the yield strength and the elastic modulus (Young) increase to $20 \%$. The microhardness of austenite and martensite after their cooling in liquid nitrogen increased with increasing nickel concentration. Tests on the toughness of alloys at negative temperatures $\left(-190^{\circ} \mathrm{C}\right)$ showed an increase in this index to $350 \mathrm{~kJ} / \mathrm{m}^{2}$ with an increase in the Ni content from 30.2 to $36.3 \%$.

With decreasing nickel concentration, an increase in the temperature range of the austenite-martensitic transformation is associated with a broad grain diameter and there is an increase in the $\gamma-\alpha$ phase transition temperature from the critical grain size, which fits within the framework of the Dynamic Wave Transformation Theory.

\section{Acknowledgment}

The work was supported by the RFBR grant, project No. 1648-59-0224.

The authors express their gratitude to Professor A. V. Korolev for the investigation of temperature austenitemartensitic transformations.

\section{References}

[1] V.A. Lobodiuk, Isothermal martensitic transformation, martensitic phase transformation, 1993

[2] V.A . Liubodiuk., E.I . Estrin, Martensitic transformations, 2009.

[3] M.P. Kashchenko, Wave model of martensite growth for $\mathrm{Y}^{-\alpha}$ transformation in iron-based alloys, 2010

[4] B. N. Babich, E. V. Vershinina, V. A. Glebov, Metallic powders and powder materials, 2005.

[5] M.S. Wechsler, D.S Lieberman, "On the theory of formation of martrnsite", Journal of metals, vol. 197, №1, pp.1503-1515, 1953.

[6] J.S. Bowles, J.K. Mackenzie, "The crystallography of martensite transformation III ", Acta Metallurgia, Vol.2, № 3, pp. 224-234, 194.

[7] O. S. Krizement, Z. I. Gudremon, F. K. Vefer, Thermodynamics of austenitic-martensitic transformation, 1961
[8] N.D. Niashina, P.V. Trusov, "Modeling of martensitic transformations in steels: kinematics of meso level," messenger PNIPU", Mechanics, № 4, pp. 118-151, 2014.

[9] V.V. Rusanenko, F.F. Edneral, O.N. Ledeneva, " Elinvar and mechanical properties of martensitic austenitic alloys", Metallurgy and heat treatment, №7, pp. 27-30, 1996.

[10] M.P. Kashchenko, V.G. Chashchina, Dynamic model of the formation of twinned martensitic crystals with $Y-\alpha$ transformation in iron alloys, 2009.

[11] M.P. Kashchenko, Wave model of martensite growth for $\mathrm{Y}^{-\alpha}$ transformation in iron-based alloys, 1993.

[12] E.A. Fokina, Zavadskii E.A., "Influence of the magnetic field on the martensitic transformation in steel ", Physics of metals and metallurgy, vol. 16, №2, pp. .311-313, 1963.

[13] G.V. Kurdiumov, The phenomena of hardening and tempering steel, 1960.

[14] M.P. Kashchenko, V.P. Vereshchagin, " Allowance for the elastic field of a rectilinear dislocation within the framework of the wave description of the growth of martensite", Proceedings of high schools, physics, № 8, pp.20-23, 1989.

[15] L.E. Kar'kina, I.N. Kar'kin, Iu.N. Gornostyrev, "Structural transformations in nanoclusters of $\mathrm{Fe}-\mathrm{Ni}$ alloy. The results of molecular dynamics simulation", FMM., vol. 101, №2, pp. 146-157, 2006.

[16] B .N. Arzamasov, Materials Science, 2004.

[17] GOST 5639-82. Steels and alloys. Method for determining the grain size, 1983

[18] GOST 9012-59 Metals. Method for determining the hardness, 2007.

[19] GOST 25095-82 Alloys hard sintered. Method for determining the modulus of longitudinal elasticity, 1983. 